\title{
The IMPACT study: a prospective evaluation of the effects of cyclosporine ophthalmic emulsion $0.05 \%$ on ocular surface staining and visual performance in patients with dry eye
}

\author{
This article was published in the following Dove Press journal: \\ Clinical Ophthalmology \\ 13 May 2016 \\ Number of times this article has been viewed
}

\author{
Karl G Stonecipher ${ }^{1,2}$ \\ Gail L Torkildsen ${ }^{3}$ \\ George W Ousler III \\ Scot Morris ${ }^{5}$ \\ Linda Villanueva ${ }^{6}$ \\ David A Hollander 6 \\ 'Department of Ophthalmology, \\ University of North Carolina, \\ Chapel Hill, ${ }^{2}$ TLC Laser Eye Centers, \\ Greensboro, NC, ${ }^{3}$ Andover Eye \\ Associates, ${ }^{4}$ Ora, Inc., Andover, \\ MA, ${ }^{5}$ Eye Consultants of Colorado, \\ Conifer, $\mathrm{CO},{ }^{6}$ Allergan plc, \\ Irvine, CA, USA
}

Objective: The aim of this study was to evaluate the effects of cyclosporine ophthalmic emulsion $0.05 \%$ on ocular surface staining and visual performance in patients with dry eye.

Methods: This was a single-center, 6-month, open-label, Phase IV study. Patients with bilateral dry eye disease and a symptom score of $\geq 2$ on the Ocular Discomfort and 4-Symptom Questionnaire, an Ocular Surface Disease Index score of $>12$, at least one eye with Schirmer's score $<10 \mathrm{~mm} / 5$ minutes, and central corneal staining graded as $\geq 2$ on the Ora Calibra ${ }^{\mathrm{TM}}$ Corneal and Conjunctival Staining Scale were enrolled. Cyclosporine ophthalmic emulsion $0.05 \%$ $\left(\right.$ Restasis $^{\circledR}$ ) was instilled twice daily in each eye. The primary efficacy endpoints were ocular surface staining and visual function at 6 months. Secondary outcome measures included Schirmer's test, tear film breakup time, symptoms, and adverse events.

Results: A total of 40 patients with the mean age of 59.4 years (range, 40-78 years) were enrolled; 35 (87.5\%) were female and 37 (92.5\%) completed the study. At 6 months, inferior corneal, central corneal, total corneal, and total ocular surface fluorescein staining were significantly improved from baseline in both eyes $(P<0.001)$. Patient responses on the Ocular Surface Disease Index showed significant improvement in blurred vision and visual function related to reading, driving at night, working with a computer or bank machine, and watching television ( $P \leq 0.041$ ). At 6 months, 35.1\% of patients achieved $\geq 5 \mathrm{~mm}$ improvement and $18.9 \%$ achieved $\geq 10 \mathrm{~mm}$ improvement in the average eye Schirmer score. Mean tear film breakup time improved by $>50 \%$ in both eyes $(P<0.001)$. Patients reported significant improvement in ocular discomfort and dry eye symptoms $(P<0.001)$. No patients discontinued treatment because of stinging or any other ocular adverse event.

Conclusion: Dry eye patients with difficulties with day-to-day visual function demonstrated improvement in both signs and symptoms of dry eye and reported improved visual function after 6 months of treatment with cyclosporine ophthalmic emulsion $0.05 \%$.

Keywords: corneal staining, dry eye disease, Ocular Surface Disease Index, ocular surface staining, visual function, clinical trial

\section{Introduction}

Dry eye is a prevalent, chronic, multifactorial disease of the tears and ocular surface. ${ }^{1,2}$ Instability of the tear film accompanied by T-cell-mediated ocular surface inflammation plays a major role in disease development and progression. ${ }^{3,4}$ Dry eye symptoms are a key complaint of patients with dry eye. Patients with dry eye suffer from symptoms of ocular discomfort, dryness, and visual disturbances, which may be episodic and also vary during the day. ${ }^{5-7}$
Correspondence: Karl G Stonecipher TLC Laser Eye Centers, 1002 North Church Street, Suite I0I, Greensboro, NC 27410, USA

Tel +I 3362888823

Email stonenc@aol.com (c) 17 (5) 2016 Stonecipher et al. This work is published and licensed by Dove Medical Press Limited. The full terms of this license are available at https://www.dovepress.com/terms.php
and incorporate the Creative Commons Attribution - Non Commercial (unported, v3.0) License (http://creativecommons.org/licenses/by-nc/3.0/). By accessing the work you BY NC and incorporate the Creative Commons Attribution - Non Commercial (unported, v3.0) License (http:///creativecommons.org/licenses/by-nc/3.0/). By accessing the work you
hereby accept the Terms. Non-commercial uses of the work are permitted without any further permission from Dove Medical Press Limited, provided the work is properly attributed. For permission hereby accept the Terms. Non-commercial uses of the work are permitted without any further permission from Dove Medions.
for commercial use of this work, please see paragraphs 4.2 and 5 of our Terms (https://www.dovepress.com/terms.php). 
Corneal staining with fluorescein is a diagnostic sign of dry eye and a key measure of dry eye in clinical studies. Additional diagnostic measures may include Schirmer tests and tear film evaluations such as tear film breakup time (TBUT). However, lack of a consistent association between the signs and symptoms of dry eye remains an impediment to accurate diagnosis and assessment of treatment efficacy. ${ }^{8,9}$

Patients with dry eye frequently report visual disturbances such as blurred or foggy vision, fluctuating vision, and problems with glare. ${ }^{5}$ A quality-of-life survey study by Miljanović et al ${ }^{10}$ showed an association between dry eye disease and patient difficulty with vision-related tasks including reading, using a computer, watching television, and driving. Subsequent studies using the National Eye Institute 25-Item Visual Function Questionnaire (NEI VFQ-25) ${ }^{11-13}$ and the disease-specific Ocular Surface Disease Index (OSDI) questionnaire have demonstrated that patients with dry eye report increased difficulty with vision-related activities compared with control subjects. ${ }^{11}$ Objective assessments have also shown a reduction in functional visual acuity and reading speed, which correlate with central corneal staining, in patients with dry eye. ${ }^{14,15}$ Impairment of driving ability due to visual disturbance in patients with dry eye also has been confirmed objectively in a study using a driving simulator. ${ }^{16}$

Topical cyclosporine ophthalmic emulsion $0.05 \%$ is an anti-inflammatory treatment that has been shown to effectively improve dry eye signs (eg, tear production and corneal staining) and symptoms (eg, blurred vision) in patients with moderateto-severe disease. ${ }^{17}$ Early treatment with cyclosporine has been associated with improvements in tear production and tear film stability, as well as reduced progression of dry eye disease. ${ }^{18,19}$ Although it has been over 12 years since the US Food and Drug Administration approval of topical cyclosporine emulsion for the treatment of dry eye, the impact of cyclosporine treatment on visual function in patients with dry eye in the real world is not widely recognized. This study was designed to better understand patient response to cyclosporine therapy and the therapeutic benefit of cyclosporine treatment in reducing signs and symptoms and improving visual function in patients diagnosed with dry eye.

\section{Methods}

This was a prospective, single-center, open-label, Phase IV study conducted at Andover Eye Associates (Andover, MA, USA) between April and September 2014 (ClinicalTrials.gov identifier: NCT02121847). The study adhered to the tenets of the Declaration of Helsinki and Good Clinical Practice.
The Alpha Independent Review Board (San Clemente, CA, USA) approved the study protocol, and all patients provided written informed consent.

To be included in the study, patients were required to be 18 years of age or older and have a history of dry eye in both eyes. At screening, patients were required to have a history of use or desire to use eye drops for dry eye symptoms within the past 6 months, report a score of $\geq 2$ for at least one of the dry eye symptoms assessed on the Ora Calibra ${ }^{\mathrm{TM}}$ Ocular Discomfort and 4-Symptom Questionnaire ${ }^{20}$ (Ora, Inc., Andover, MA, USA), report a composite OSDI score of $>12$ with a score of $\geq 2$ on the vision-related function subscale of the OSDI, and have at least one eye with the following: a Schirmer test score (without anesthesia) of $<10 \mathrm{~mm} / 5$ minutes, corneal fluorescein staining graded as $\geq 2$ and $<4$ in at least one region and central corneal fluorescein staining graded as $\geq 2$ on the Ora Calibra ${ }^{\mathrm{TM}}$ Corneal and Conjunctival Staining Scale, ${ }^{20}$ and a conjunctival redness score of $\geq 1$ on the Ora Calibra ${ }^{\mathrm{TM}}$ Conjunctival Redness Scale. ${ }^{20}$

Key exclusion criteria at screening included ongoing ocular infection, clinically significant slit-lamp findings such as active blepharitis, meibomian gland dysfunction, lid margin inflammation, or ocular allergies requiring treatment or that in the opinion of the investigator might interfere with interpretation of the study results, use of cyclosporine ophthalmic emulsion $0.05 \%$ within the past 90 days, use of any eye drop within the past 2 hours, ocular or lid surgery within the past 6 months, keratomileusis surgery within the past 12 months or previous cataract surgery at any time in either eye, required use of any medication known to cause ocular drying or affect dry eye unless on a dosing regimen that had been stable for 30 days and would remain stable during the study, and best-corrected visual acuity of $+0.6 \log$ MAR $(\sim 20 / 80$ Snellen equivalent) or worse in both eyes.

Consecutive patients who met the study eligibility criteria were enrolled and dispensed cyclosporine ophthalmic emulsion $0.05 \%$ (Restasis $^{\circledR}$; Allergan plc, Dublin, Ireland). Patients were instructed to instill the study medication twice daily in both eyes for 6 months. Refresh Optive ${ }^{\circledR}$ advanced artificial tears (Allergan plc) were also provided to patients for use as needed.

Study visits were at day 0 (screening/baseline), month 1 , and month 6 . The primary efficacy endpoints were ocular surface staining and visual function at 6 months. Secondary efficacy endpoints were the Schirmer tear test, TBUT, blink patterns, and dry eye symptoms.

Corneal and conjunctival staining were evaluated at each visit. Fluorescein corneal staining (central, inferior, and 
superior regions, and their total) and fluorescein and lissamine green conjunctival staining (nasal and temporal regions) in each eye were graded on the Ora Calibra ${ }^{\mathrm{TM}}$ Corneal and Conjunctival Staining Scale (0-4 scale with 0.5 increments, where 0 is no staining and 4 is severe staining). Conjunctival fluorescein staining scores were added to the total corneal fluorescein staining score to generate an all-region combined score of ocular surface staining.

Visual function was assessed by patient responses on the OSDI questionnaire at baseline and month 6. Schirmer tear test without anesthesia and TBUT were assessed in each eye at baseline and month 6 . Blink patterns were assessed in each eye over a period of 3 minutes using the automated Ocular Protection Index 2.0 System (Ora, Inc.) ${ }^{21}$ at baseline, month 1, and month 6 . This system measures blink frequency, which is used to calculate the interblink interval (time between blinks). Severity of dry eye symptoms was assessed with the Ora Calibra $^{\text {TM }}$ Ocular Discomfort and 4-Symptom Questionnaire at baseline and month 6 . This questionnaire evaluates overall ocular discomfort, dryness, grittiness, burning, and stinging on a 6-point visual analog scale of 0 (none) to 5 (worst).

Safety outcome measures at each visit included adverse events, best-corrected visual acuity evaluated using an Early Treatment Diabetic Retinopathy Study (ETDRS) chart, and slit-lamp biomicroscopy. Adverse events and compliance with the dosing schedule were elicited at each visit, as well as in telephone calls to patients at week 2 and months 2, 3, 4 , and 5.

Efficacy parameters were evaluated using observed values in the intent-to-treat population of all enrolled patients. Safety parameters were evaluated in the safety population of all patients who received cyclosporine treatment. The worse eye was defined as the eye with worse central corneal staining at baseline. If baseline staining was the same in each eye, the right eye was designated the worse eye.

Ocular surface staining, TBUT, and interblink interval were analyzed separately in worse treated eyes and fellow treated eyes. The analysis of Schirmer test results used the average value from both treated eyes. Statistical analysis comparing signs and symptoms after 6 months of cyclosporine treatment with those at baseline used the paired $t$-test or Wilcoxon signed-rank test and an alpha level of 0.05 .

\section{Results}

A total of 40 patients were enrolled in the study. The mean ( \pm standard deviation $[\mathrm{SD}])$ age of the patients was $59.4 \pm 9.1$ years (range, $40-78)$. Thirty-five $(87.5 \%)$ of the patients were female, and all were Caucasian.
Thirty-seven patients (92.5\%) completed the 6-month study. Two patients discontinued from the study because of non-ocular adverse events (one patient with injuries from an automobile accident, and one patient with headache), and one patient discontinued from the study for administrative reasons.

\section{Efficacy}

Total ocular surface staining scores were significantly reduced from baseline at month 6 in both worse treated eyes and fellow treated eyes $(P<0.001)$. A significant reduction in corneal staining from baseline was observed for total cornea, central cornea, and inferior cornea in both the worse and fellow treated eyes following 6 months of treatment $(P<0.001$; Figure 1). The largest reductions from baseline in staining were seen in total cornea $(26.9 \%$ in worse and $29.1 \%$ in fellow treated eyes) and central cornea (58.4\% in worse and $52.1 \%$ in fellow treated eyes).

The mean ( \pm standard error of the mean) composite OSDI score improved from $47.0 \pm 2.7$ (indicating severe disease) at baseline to $26.8 \pm 3.0$ (indicating moderate disease) at month $6(P<0.001)$. Patient responses on the visual functioning subscale of the OSDI (four questions concerning eye problems causing difficulty in reading, driving at night, working with a computer or bank machine, and watching television within the past week) indicated that visual function related to all four tasks improved significantly after 6 months of cyclosporine treatment (Figure 2). In addition, patient responses to OSDI questions regarding symptoms of poor visual function (ie, blurred vision and poor vision within the past week) indicated that the frequency of both symptoms decreased significantly after 6 months of cyclosporine treatment (Figure 2).

Mean average eye Schirmer test scores increased significantly from $5.3 \mathrm{~mm}$ at baseline to $8.7 \mathrm{~mm}$ at month 6 ( $P=0.010$; Figure 3$)$. At month $6,35.1 \%$ of patients $(13 / 37)$ achieved at least $5 \mathrm{~mm}$ improvement in the average eye Schirmer score, and $18.9 \%$ of patients (7/37) achieved at least $10 \mathrm{~mm}$ improvement in the Schirmer score.

Significant improvements in TBUT compared with baseline values were observed at month 6 in both worse treated eyes $(P<0.001$; Figure 4A) and fellow treated eyes $(P<0.001)$. The mean increase in TBUT was 0.92 seconds (59.4\%) from a baseline value of 1.55 seconds in worse treated eyes and 0.78 seconds $(55.7 \%)$ from a baseline value of 1.40 seconds in fellow treated eyes. The increase in tear film stability was accompanied by a significant decrease in blink frequency $(P=0.004$; Figure $4 \mathrm{~B})$. The mean increase 

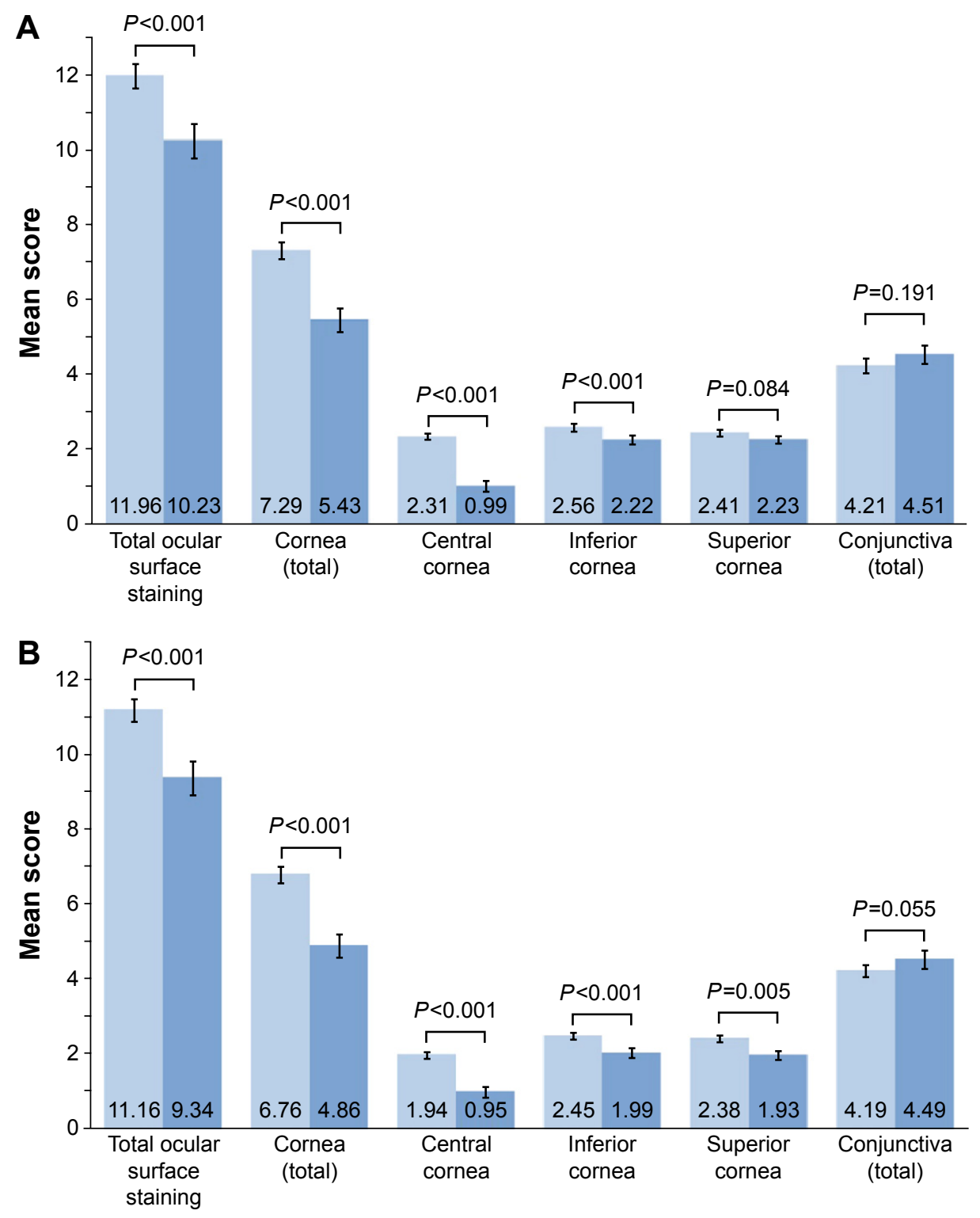

Baseline $(\mathrm{n}=40) \quad$ Month $6(\mathrm{n}=37)$

Figure I Ocular surface staining at baseline and month 6 .

Notes: Both eyes of patients were treated with cyclosporine for 6 months. The worse eye was defined as the eye with the worse central corneal staining at baseline. Mean scores of fluorescein corneal and total ocular surface staining and lissamine green conjunctival staining in the worse treated eyes (A) and fellow treated eyes (B) are shown. $P$-values are from paired $t$-tests. Error bars indicate standard error of the mean.

in interblink interval was 3.04 seconds $(72.7 \%)$ in worse treated eyes.

Patient responses on the Ora Calibra ${ }^{\mathrm{TM}}$ Ocular Discomfort and 4-Symptom Questionnaire at month 6 indicated a significant reduction from baseline in ocular discomfort and each symptom $(P<0.001$; Figure 5$)$. The mean decrease in scores was $1.30(45.6 \%)$ for ocular discomfort, $1.46(46.6 \%)$ for dryness, $1.14(60.0 \%)$ for grittiness, $0.84(49.4 \%)$ for burning, and 1.11 (61.7\%) for stinging.

\section{Safety}

All patients were treated with cyclosporine and were included in the safety population. Adverse events were reported in 17 patients $(42.5 \%)$. Ocular adverse events were reported in ten patients $(25 \%)$, most commonly instillation site burn (three patients, 7.5\%), instillation site pain (three patients, $7.5 \%$ ), and eye irritation (two patients, $5 \%$ ). Only one patient (2.5\%) had a non-ocular treatment-emergent adverse event (headache) that was considered to be related to treatment. 


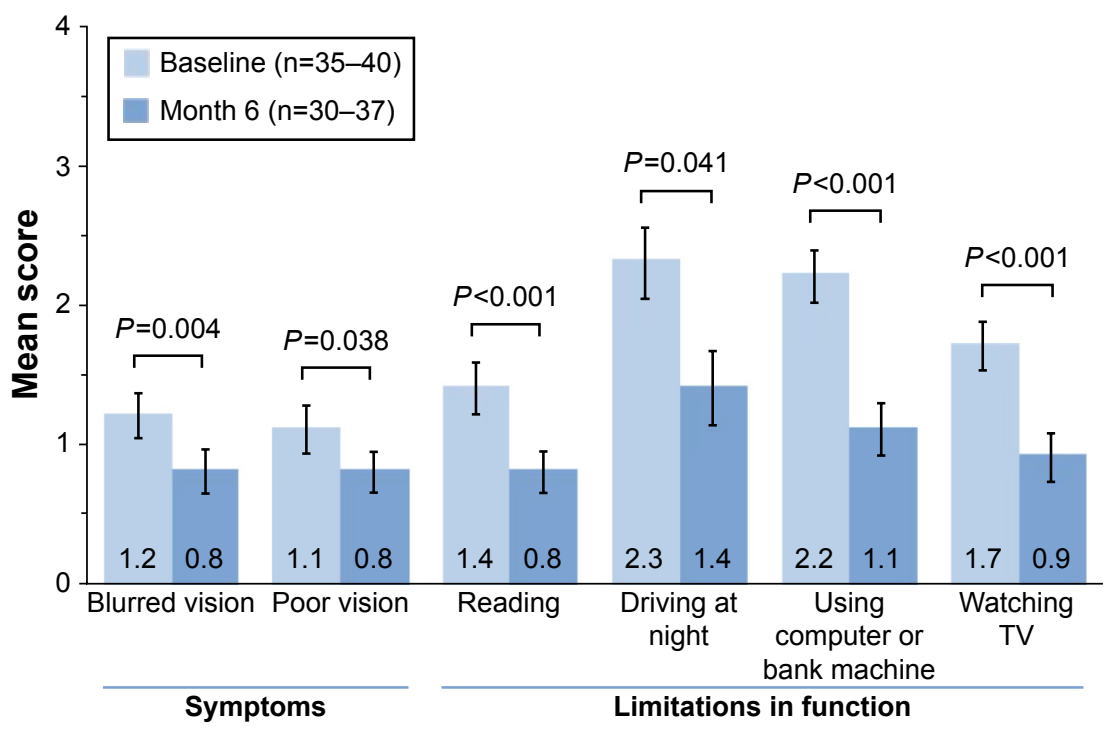

Figure 2 Mean scores related to visual function on the OSDI.

Notes: The occurrence of symptoms of poor visual function within the past week and limitations in the performance of tasks due to problems with the patient's eyes within the past week were evaluated on the OSDI at baseline and month 6 . Scores could range from 0 to 4 with $0=$ none of the time, $I=$ some of the time, $2=$ half of the time, $3=$ most of the time, and $4=$ all of the time. $P$-values are from paired $t$-tests. Error bars indicate the standard error of the mean.

Abbreviations: OSDI, ocular surface disease index; TV, television.

There were no safety concerns on biomicroscopy or visual acuity testing, and no anatomical changes were observed. Mean best-corrected visual acuity in worse treated eyes was $0.083 \log$ MAR ( $20 / 25$ Snellen equivalent $)$ at baseline and $0.085 \log \operatorname{MAR}(\sim 20 / 25$ Snellen equivalent) at month 6 . In fellow treated eyes, mean best-corrected visual acuity was $0.062 \log$ MAR ( $20 / 25$ Snellen equivalent) at baseline and $0.049 \log$ MAR (20/20 Snellen equivalent) at month 6 .
No patient had a clinically relevant treatment-related decrease in best-corrected visual acuity.

\section{Compliance}

Patients generally reported being compliant with twice-daily dosing of cyclosporine ophthalmic emulsion $0.05 \%$ during the 6-month study period, with $<3 \%$ of total doses missed across all patients.
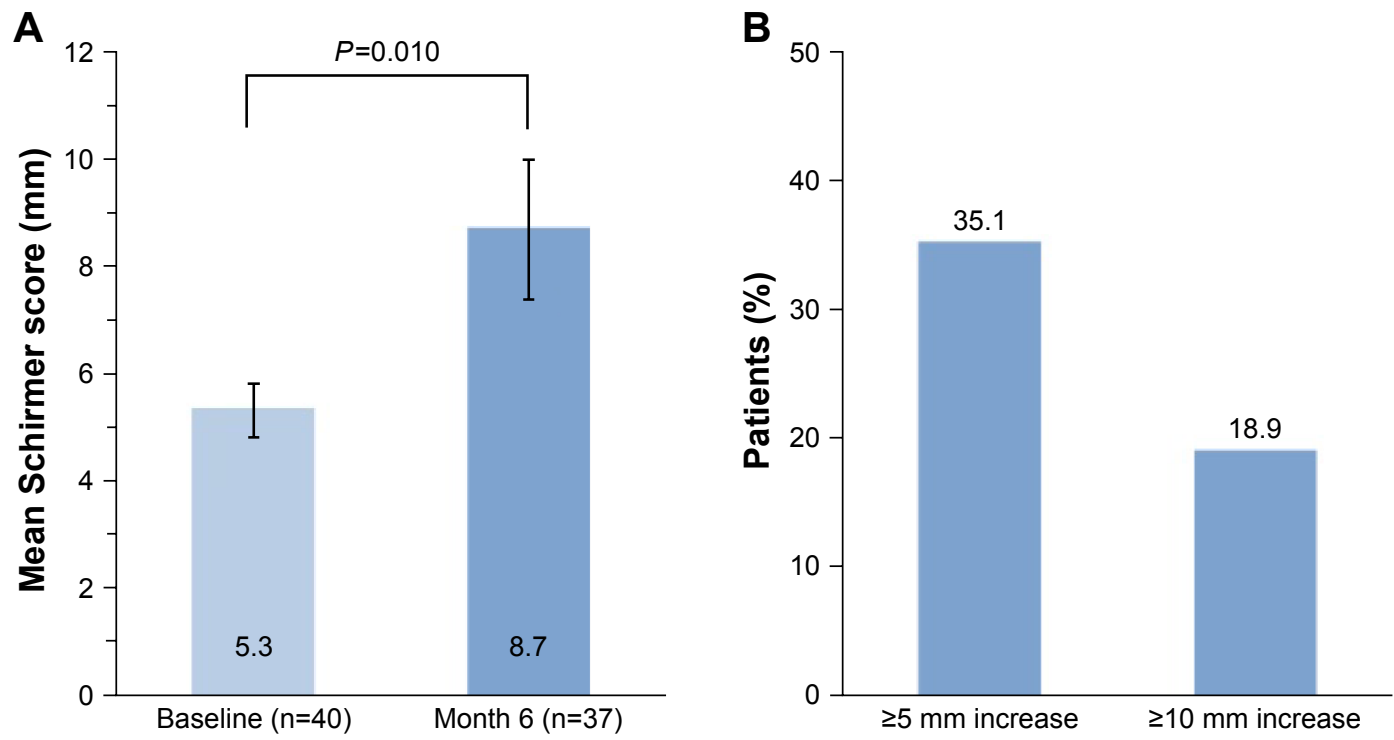

Figure 3 Tear production.

Notes: (A) Mean average eye Schirmer test scores at baseline and month 6. Error bars indicate standard error of the mean. (B) Percentage of patients who achieved at least a $5 \mathrm{~mm}$ or $10 \mathrm{~mm}$ increase from baseline in average eye Schirmer test scores at month $6 . P$-value is from a paired $t$-test. 
A

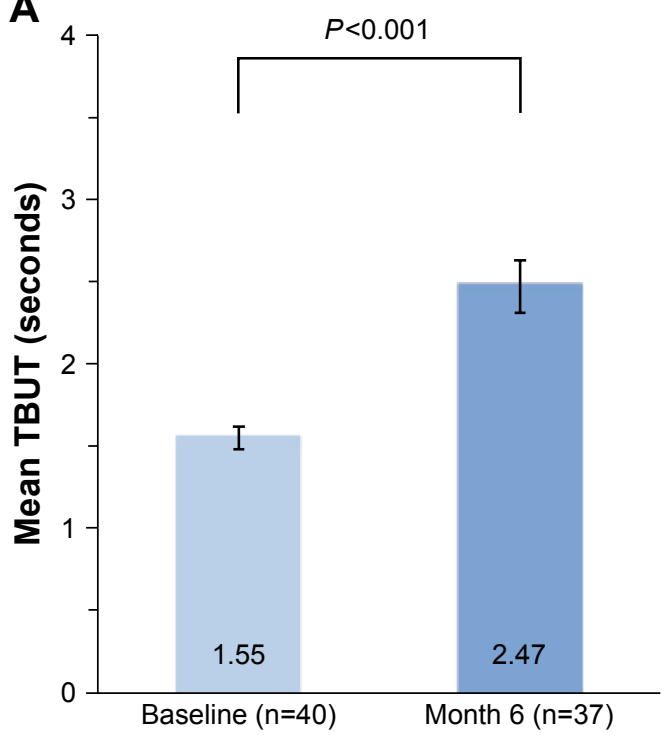

B

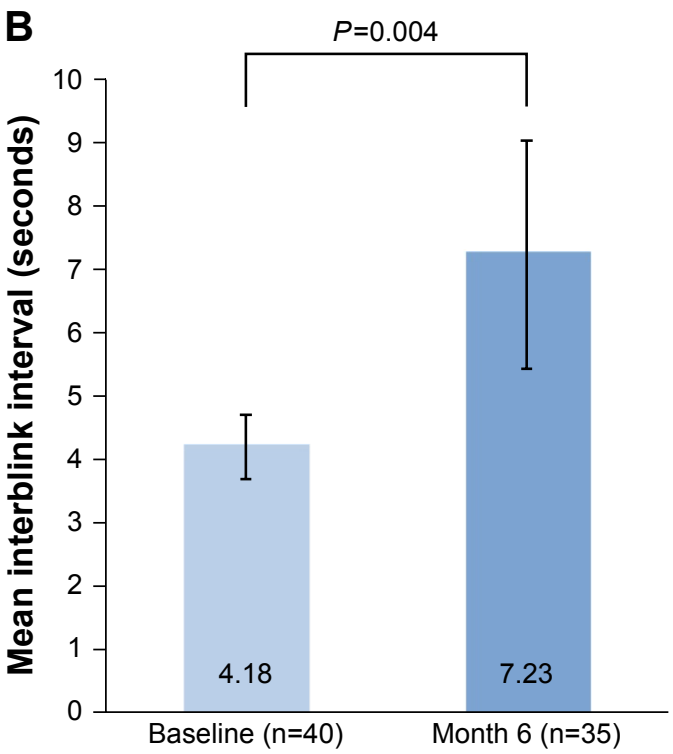

Figure 4 Mean (A) TBUT and (B) interblink interval in worse treated eyes at baseline and month 6.

Notes: Interblink interval is defined as the time between blinks. $P$-values are from a paired $t$-test (A) or the Wilcoxon signed-rank test (B). Error bars indicate standard error of the mean.

Abbreviation: TBUT, tear film breakup time.

\section{Discussion}

Dry eye is frequently associated with visual disturbances. The patients selected for this study had difficulties with daily activities related to visual function, as well as ocular surface damage seen with fluorescein staining, and both improved after twice-daily treatment with cyclosporine ophthalmic emulsion $0.05 \%$. After 6 months of treatment, patient responses on the OSDI showed a significant reduction in the frequency of blurred vision and significant improvement in visual functioning related to reading, night driving, computer or bank machine use, and watching television. Total corneal staining and staining in the central corneal region, which is known to be critical to visual function, had decreased significantly from baseline.

Patients also demonstrated clinically significant improvements in other signs and symptoms of dry eye disease. Consistent with the approved indication for cyclosporine ophthalmic emulsion for the increase in tear production in patients whose tear production is presumed to be suppressed due to ocular inflammation associated with keratoconjunctivitis sicca,

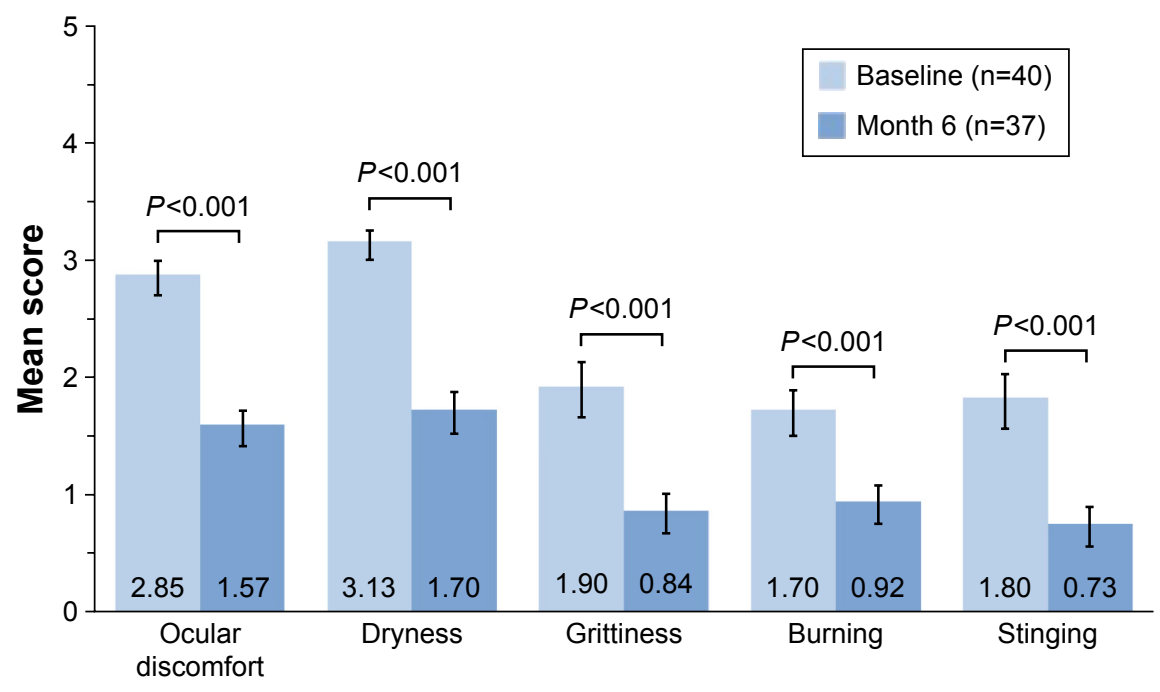

Figure 5 Mean scores on the Ora Calibra ${ }^{\text {TM }}$ Ocular Discomfort and 4-Symptom Questionnaire at baseline and month 6. Notes: $P$-values are from paired $t$-tests. Error bars indicate standard error of the mean. 
sizable increases $(>60 \%)$ were observed in tear production measured with the Schirmer test. A similar magnitude of improvement was seen in tear film stability and interblink intervals. Patient-reported outcomes of ocular discomfort and other symptoms of dry eye also were significantly improved. The mean composite OSDI score improved by almost $50 \%$, with the mean score indicating severe disease at baseline and moderate disease following 6 months of cyclosporine treatment. Patients reported excellent compliance with the dosing schedule, and treatment was well tolerated. Notably, no patient discontinued the use of cyclosporine because of stinging upon instillation.

Dry eye is underdiagnosed and potentially undertreated. ${ }^{22}$ In a prospective study of the prevalence of dry eye in 136 patients who presented to nine clinical sites in the US for cataract surgery and were not being treated with topical cyclosporine, $81 \%$ had moderate-to-severe dry eye based on International Task Force criteria, yet only $22 \%$ had a previous diagnosis of dry eye. ${ }^{23}$ Most of the patients (63\%) had a TBUT of 5 seconds or less, and a majority of the eyes (77\%) had corneal staining with central staining present in half of the eyes $(50 \%)$.

The ocular discomfort and visual disturbances associated with untreated dry eye have a negative impact on the quality of life of affected individuals. In the ongoing PROOF study of the natural history of dry eye disease, the majority of patients with International Task Force Level 2 (moderate) dry eye reported moderate, severe, or very severe blurred or fluctuating vision that made them uncomfortable at baseline. ${ }^{24}$ In the PROOF study, as in this study, baseline mean bestcorrected visual acuity as measured on a standard Snellen eye chart was $\sim 20 / 25$. These findings reinforce the need for vision assessments beyond standard visual acuity testing. Evaluations should include the potential impact of dry eye disease on the patient's quality of vision and day-to-day visual functioning.

The beneficial effects of cyclosporine ophthalmic emulsion treatment on the signs and symptoms of dry eye in this open-label study are consistent with the previously reported effects of cyclosporine treatment in controlled clinical trials. The percentage of patients with at least a $10 \mathrm{~mm}$ increase in Schirmer's test (without anesthesia) scores at month 6 was $18.9 \%$, similar to results in the Phase III registration trials of cyclosporine $0.05 \%$ emulsion, where $\sim 15 \%$ of patients treated with cyclosporine versus $5 \%$ treated with vehicle had at least a $10 \mathrm{~mm}$ increase from baseline Schirmer's test (with anesthesia) scores after 6 months of treatment. ${ }^{25}$ The improvement in tear production ( $>3 \mathrm{~mm}$ on average) was similar to the significant increase from $3.93 \pm 1.21 \mathrm{~mm}$ at baseline to $7.30 \pm 1.79 \mathrm{~mm}$ after 3 months of cyclosporine ophthalmic emulsion $0.05 \%$ treatment that was reported in a study by Kim et al. ${ }^{26}$ In a study by Demiryay et al, ${ }^{27}$ the increase in mean Schirmer scores from baseline after 4 months was $3.33 \mathrm{~mm}$ greater in patients treated with cyclosporine ophthalmic emulsion $0.05 \%$ than in patients treated with vehicle. ${ }^{28}$

The decrease in corneal fluorescein staining seen in this study, particularly in the region of the central cornea, likely contributed to the improvement in blurred vision reported by patients and is consistent with results of previous studies. In the cyclosporine ophthalmic emulsion $0.05 \%$ Phase III pivotal trials, fluorescein corneal staining and lissamine green interpalpebral conjunctival staining, measured on the Oxford scale, decreased during follow-up in both the cyclosporine and the vehicle treatment groups, but the reduction in corneal staining was significantly greater in patients treated with cyclosporine $0.05 \%$ than in patients treated with vehicle at 4 months and 6 months. ${ }^{17}$ Significant decreases in corneal staining were also observed after 3 months or 4 months of cyclosporine $0.05 \%$ treatment in the studies by Kim et al ${ }^{26}$ and Demiryay et al. ${ }^{27}$

Each blink reforms the tear film and protects the ocular surface. Patients with dry eye blink more frequently because of tear film instability, but blinking too often may interfere with visual tasks or lead to visual fatigue. In this study, improvement in tear film stability after 6 months of cyclosporine treatment resulted in a significant increase in the interblink interval. These results are consistent with patient-reported improved performance on tasks related to visual function after 6 months.

Topical cyclosporine has been used successfully in the treatment of a number of ocular surface diseases in addition to dry eye..$^{29}$ The improvement in tear film stability provided by topical cyclosporine and its anti-inflammatory effects on meibomian glands have been shown to be beneficial in patients with meibomian gland dysfunction. ${ }^{30,31}$ Topical cyclosporine has also been shown to be an effective anti-inflammatory treatment for vernal and atopic keratoconjunctivitis. ${ }^{29,32,33}$ Studies have demonstrated that topical cyclosporine reduces contact lens intolerance in contact lens wearers with dry ey $\mathrm{e}^{34}$ and improves signs and symptoms in patients with ocular rosacea $^{35}$ as well as superior limbic keratoconjunctivitis. ${ }^{36}$ Most recent studies of cyclosporine treatment in ocular surface disease other than dry eye have used topical cyclosporine $(0.5 \%-2 \%)$ or cyclosporine ophthalmic emulsion $0.05 \%$ $\left(\right.$ Restasis $^{\circledR}$ ) off-label. Restasis ${ }^{\circledR}$ is indicated to increase tear 
production in patients whose tear production is presumed to be suppressed due to ocular inflammation associated with keratoconjunctivitis sicca. ${ }^{25}$

A limitation of this study was the lack of a control group. The study was open label to allow the evaluation of cyclosporine ophthalmic emulsion $0.05 \%$ effects in patients with dry eye when both eyes are treated. Data are already available from controlled clinical trials evaluating treatment versus no treatment. However, a primary objective in this study was to examine visual function, a patient-level outcome influenced by both eyes.

Day-to-day real-world visual functioning is impaired in dry eye disease and can improve with treatment. The results of this study confirm the clinical benefit of cyclosporine ophthalmic emulsion $0.05 \%$ treatment for patients with dry eye. Cyclosporine $0.05 \%$ emulsion treatment reduced the signs and symptoms of dry eye and improved the performance of patients on common vision-related tasks. Patients reported very good compliance with treatment. No patient discontinued the use of cyclosporine because of ocular intolerability, and only one systemic adverse event (headache) considered to be related to treatment was reported.

\section{Acknowledgments}

This study was sponsored by Allergan plc, Dublin, Ireland. Writing and editorial assistance was provided to the authors by Kate Ivins, PhD, of Evidence Scientific Solutions (Philadelphia, PA, USA), and funded by Allergan plc. Neither honoraria nor payments were made for authorship.

Presented in part at the American Society of Cataract \& Refractive Surgery Annual Meeting, April 17-21, 2015, San Diego, CA, USA, and at the Association for Research in Vision and Ophthalmology Annual Meeting, May 3-7, 2015, Denver, CO, USA.

\section{Author contributions}

All authors contributed toward data interpretation, drafting and critically revising the paper, gave final approval of the version to be published, and agree to be accountable for all aspects of the work.

\section{Disclosure}

Karl G Stonecipher is a consultant for Abbott Medical Optics, Alcon, Allergan, Bausch \& Lomb, Laser ACE, Nidek, Presbia, Refocus Group, and STAAR Surgical; an employee of TLC Laser Eye Centers; and has personal financial interest in Alphaeon. Gail L Torkildsen is a consultant for Ora, Inc. George W Ousler III is an employee of Ora, Inc. Scot Morris is a consultant for Allergan, Bausch \& Lomb, Essilor, Gateway Professional Network, and Marco and a speaker/educator for Alcon, Allergan, Essilor, Marco, and Vistakon. He has received grants from Alcon, Allergan, Biosciences, Essilor Laboratories of America, and Luxottica. Linda Villanueva and David A Hollander are employees of Allergan, plc. The authors report no other conflicts of interest in this work.

\section{References}

1. [No authors listed]. The definition and classification of dry eye disease: report of the Definition and Classification Subcommittee of the International Dry Eye WorkShop (2007). Ocul Surf. 2007;5(2):75-92.

2. [No authors listed]. The epidemiology of dry eye disease: report of the Epidemiology Subcommittee of the International Dry Eye WorkShop (2007). Ocul Surf. 2007;5(2):93-107.

3. Pflugfelder SC, Corrales RM, de Paiva CS. T helper cytokines in dry eye disease. Exp Eye Res. 2013;117:118-125.

4. Stevenson W, Chauhan SK, Dana R. Dry eye disease: an immune-mediated ocular surface disorder. Arch Ophthalmol. 2012;130(1):90-100.

5. Uchino M, Schaumberg DA. Dry eye disease: impact on quality of life and vision. Curr Ophthalmol Rep. 2013;1(2):51-57.

6. Dogru M, Tsubota K. Pharmacotherapy of dry eye. Expert Opin Pharmacother. 2011;12(3):325-334.

7. Ridder WH 3rd, Tomlinson A, Huang JF, Li J. Impaired visual performance in patients with dry eye. Ocul Surf. 2011;9(1):42-55.

8. Sullivan BD, Crews LA, Messmer EM, et al. Correlations between commonly used objective signs and symptoms for the diagnosis of dry eye disease: clinical implications. Acta Ophthalmol. 2014;92(2): 161-166.

9. Schmidl D, Witkowska KJ, Kaya S, et al. The association between subjective and objective parameters for the assessment of dry-eye syndrome. Invest Ophthalmol Vis Sci. 2015;56(3):1467-1472.

10. Miljanović B, Dana R, Sullivan DA, Schaumberg DA. Impact of dry eye syndrome on vision-related quality of life. Am J Ophthalmol. 2007; 143(3):409-415.

11. Li M, Gong L, Chapin WJ, Zhu M. Assessment of vision-related quality of life in dry eye patients. Invest Ophthalmol Vis Sci. 2012;53(9): $5722-5727$

12. Le Q, Zhou X, Ge L, Wu L, Hong J, Xu J. Impact of dry eye syndrome on vision-related quality of life in a non-clinic-based general population. BMC Ophthalmol. 2012;12:22.

13. Paulsen AJ, Cruickshanks KJ, Fischer ME, et al. Dry eye in the Beaver Dam offspring study: prevalence, risk factors, and health-related quality of life. Am J Ophthalmol. 2014;157(4):799-806.

14. Kaido M, Matsumoto Y, Shigeno Y, Ishida R, Dogru M, Tsubota K. Corneal fluorescein staining correlates with visual function in dry eye patients. Invest Ophthalmol Vis Sci. 2011;52(13):9516-9522.

15. Ridder WH 3rd, Zhang Y, Huang JF. Evaluation of reading speed and contrast sensitivity in dry eye disease. Optom Vis Sci. 2013;90(1): $37-44$.

16. Deschamps N, Ricaud X, Rabut G, Labbe A, Baudouin C, Denoyer A. The impact of dry eye disease on visual performance while driving. Am J Ophthalmol. 2013;156(1):e3.184-e3.189.

17. Sall K, Stevenson OD, Mundorf TK, Reis BL. CsA Phase III Study Group. Two multicenter, randomized studies of the efficacy and safety of cyclosporine ophthalmic emulsion in moderate to severe dry eye disease. Ophthalmology. 2000;107(4):631-639.

18. Rao SN. Topical cyclosporine $0.05 \%$ for the prevention of dry eye disease progression. J Ocul Pharmacol Ther. 2010;26(2):157-164.

19. Stevenson D, Tauber J, Reis BL. Efficacy and safety of cyclosporin A ophthalmic emulsion in the treatment of moderate-to-severe dry eye disease: a dose-ranging, randomized trial. Cyclosporin A Phase II Study Group. Ophthalmology. 2000;107(5):967-974. 
20. Ousler G 3rd, Devries DK, Karpecki PM, Ciolino JB. An evaluation of Retaine $^{\mathrm{TM}}$ ophthalmic emulsion in the management of tear film stability and ocular surface staining in patients diagnosed with dry eye. Clin Ophthalmol. 2015;9:235-243.

21. Abelson R, Lane KJ, Rodriguez J, et al. Validation and verification of the OPI 2.0 System. Clin Ophthalmol. 2012;6:613-622.

22. McDonnell PJ. Dry eye: an underrecognized and undertreated disease. Johns Hopkins Adv Stud Ophthalmol. 2012;9(1):14.

23. Trattler WB [webpage on the Internet]. Prevalence of dry eye in surgical populations. ASCRS EyeWorld CME Supplement. Vol. 3. 2013. Available from: http://www.eyeworld.org/supplements/oct-2013/ Allergan_supplement_October2013.pdf. Accessed September 5, 2015.

24. McDonnell PJ, Pflugfelder S, Schiffman RM, et al. Progression of Ocular Findings (PROOF) study of the natural history of dry eye: study design and baseline patient characteristics. Invest Ophthalmol Vis Sci. 2013; 54(15):4338. ARVO E-Abstract 4338.

25. Restasis ${ }^{\circledR}$ (cyclosporine ophthalmic emulsion) [prescribing information]. Irvine, CA: Allergan, Inc; 2014

26. Kim EC, Choi JS, Joo CK. A comparison of vitamin a and cyclosporine a $0.05 \%$ eye drops for treatment of dry eye syndrome. Am J Ophthalmol. 2009;147(2):e3.206-e3.213.

27. Demiryay E, Yaylali V, Cetin EN, Yildirim C. Effects of topical cyclosporine A plus artificial tears versus artificial tears treatment on conjunctival goblet cell density in dysfunctional tear syndrome. Eye Contact Lens. 2011;37(5):312-315.
28. Wan KH, Chen LJ, Young AL. Efficacy and safety of topical $0.05 \%$ cyclosporine eye drops in the treatment of dry eye syndrome: a systematic review and meta-analysis. Ocul Surf. 2015;13(3):213-225.

29. Utine CA, Stern M, Akpek EK. Clinical review: topical ophthalmic use of cyclosporin A. Ocul Immunol Inflamm. 2010;18(5):352-361.

30. Prabhasawat P, Tesavibul N, Mahawong W. A randomized double-masked study of $0.05 \%$ cyclosporine ophthalmic emulsion in the treatment of meibomian gland dysfunction. Cornea. 2012;31(12):1386-1393.

31. Qiao J, Yan X. Emerging treatment options for meibomian gland dysfunction. Clin Ophthalmol. 2013;7:1797-1803.

32. Wan KH, Chen LJ, Rong SS, Pang CP, Young AL. Topical cyclosporine in the treatment of allergic conjunctivitis: a meta-analysis. Ophthalmology. 2013;120(11):2197-2203.

33. Zicari AM, Zicari A, Nebbioso M, et al. High-mobility group box-1 (HMGB-1) and serum soluble receptor for advanced glycation end products (sRAGE) in children affected by vernal keratoconjunctivitis. Pediatr Allergy Immunol. 2014;25(1):57-63.

34. Hom MM. Use of cyclosporine $0.05 \%$ ophthalmic emulsion for contact lens-intolerant patients. Eye Contact Lens. 2006;32(2):109-111.

35. Schechter BA, Katz RS, Friedman LS. Efficacy of topical cyclosporine for the treatment of ocular rosacea. Adv Ther. 2009;26(6):651-659.

36. Sahin A, Bozkurt B, Irkec M. Topical cyclosporine A in the treatment of superior limbic keratoconjunctivitis: a long-term follow-up. Cornea. 2008;27(2):193-195.
Clinical Ophthalmology

\section{Publish your work in this journal}

Clinical Ophthalmology is an international, peer-reviewed journal covering all subspecialties within ophthalmology. Key topics include: Optometry; Visual science; Pharmacology and drug therapy in eye diseases; Basic Sciences; Primary and Secondary eye care; Patien Safety and Quality of Care Improvements. This journal is indexed on

Submit your manuscript here: http://www.dovepress.com/clinical-ophthalmology-journal

\section{Dovepress}

PubMed Central and CAS, and is the official journal of The Society of Clinical Ophthalmology (SCO). The manuscript management system is completely online and includes a very quick and fair peer-review system, which is all easy to use. Visit http://www.dovepress.com/ testimonials.php to read real quotes from published authors. 